\title{
Formação x educação, Deontologia x ética: repensando conceitos, reposicionando docentes
}

\author{
Mirelle Finkler*; Daniel Philippi de Negreiros** \\ * Doutora em Odontologia, Departamento de Odontologia e \\ Programas de Pós-Graduação em Odontologia e em Saúde \\ Coletiva da UFSC \\ ** Médico psiquiatra, Mestre em Ciências Médicas, UFSC
}

Recebido em 27/11/2017. Aprovado em 21/03/2018.

\begin{abstract}
RESUMO
Partindo de inquietações e reflexões docentes, buscamos problematizar alguns conceitos frequentemente tomados como sinônimos no contexto da educação de profissionais de saúde, descortinando concepções alternativas para um fazer pedagógico eticamente comprometido. A análise se centra na ideia hegemônica da ética que conforma certo sentido para a expressão "ética na formação", em contraposição ao que se poderia denominar de uma "dimensão ética da educação". Por meio de uma escrita dialógica sobre temas comuns a todo (a) professor (a), quer-se provocar o (a) leitor (a) para o exame de sua práxis acadêmica e para o questionamento sobre o que temos realizado na universidade: formação profissional ou educação superior? Os argumentos expressos neste ensaio almejam fomentar o (auto)questionamento para que cada um(a) responda, a sua maneira, e depois coletivamente, à pergunta essencial que a ética nos faz: "que devo(devemos) fazer"?

Descritores: Ética. Desenvolvimento Moral. Educação Superior. Formação Profissional. Universidade.
\end{abstract}

1 DA "ÉTICA NA FORMAÇÃO" PARA UMA "DIMENSÃO ÉTICA DA EDUCAÇÃO SUPERIOR"

Não seria surpresa que o leitor ou a leitora deste texto sentisse algum estranhamento ou inquietude já no momento de se decidir pela leitura (ou não) do que segue, a partir do resumo. Ali usamos o termo "dimensão ética da educação" superior ou universitária, ao invés das expressões mais habituais - "ética na formação profissional" ou mesmo "formação profissional ética". Cabe então, por zelo e elucidação, explicar que nos referimos à educação superior em contraste à formação profissional, de propósito, para demarcar uma disputa de visões. Um embate de concepções sobre a função da 
universidade nas sociedades contemporâneas, sobre sua missão em nosso imaginário social e acadêmico $^{1}$.

De um lado, uma universidade progressista que prioriza a eficácia e a eficiência na "formação profissional" a serviço da comunidade social e política, a serviço do mercado. Por outro, uma ideia de universidade clássica, que preza pela excelência (profissional e pessoal) por meio da "educação universitária", que seria uma "formação humanística"1,2 direcionada ao desenvolvimento de cidadãos, pessoas plenas, íntegras, autônomas, responsáveis e prudentes ${ }^{3}$. Uma universidade que deveria orientar a sociedade sobre o que necessita e sobre o que lhe deveria interessar, não respondendo tão somente às suas demandas ${ }^{1}$. Que entende e acolhe o inexorável papel transformador que tem na vida dos que nela adentram. Que se responsabiliza por ele e por isso fomenta a construção pessoal, oferecendo subsídios para que seus egressos não apenas façam bem, mas também, façam o bem.

Trata-se de concepções complementares que coexistem e que se retroalimentam, ainda que atuem como forças em direções opostas, em permanente tensão. Mas o equilíbrio entre elas tem sido realmente difícil, como muitos de nós, professores, podemos comprovar. A dita "formação profissional" tem sido a tônica da universidade contemporânea que atribui à educação moral e cultural menor valor ${ }^{4}$, negligenciando assim o caráter humano daqueles que serão os responsáveis por atender os anseios de uma população, também cada vez mais negligenciada. E que justamente por permanecer desassistida em sua humanidade, frustra-se ao receber técnica sem solidariedade, atendimento sem empatia, tratamento sem cuidado. E assim retorna, como em uma porta giratória, ao ponto de início, esperando, quem sabe um dia, de fato ser atendida.

Cabe pontuar aqui, que compreendemos a educação moral como um "processo que envolve cada sujeito na construção sociocultural de sua personalidade moral"s. É uma construção por não ser uma imposição de modelos externos, nem o simples descobrimento de valores internos, nem ainda o desenvolvimento de certas capacidades morais. Mas um processo destinado a dar forma à própria identidade, e por isso mesmo, processo de construção de uma personalidade moral. Algo complexo, que envolve desde a aquisição de convenções sociais até a configuração da consciência moral autônoma, desde reflexões e juízos até sentimentos e comportamentos. Uma obra ao mesmo tempo própria e compartilhada - feita junto com os demais. Assim, "a educação moral, mais do que um espaço contíguo a outros espaços educativos, é uma dimensão formativa que atravessa todos os âmbitos da educação e da personalidade" $"$.

\section{A EDUCAÇÃO SUPERIOR COMO LÓCUS PARA A CONSTRUÇÃO DA PERSONALI- DADE MORAL}

É fato comprovado por diferentes pesquisas que estudantes de Medicina ${ }^{6,7}$, Odontologia $^{8}$ e Enfermagem $^{9}$ sofrem um processo de estagnação e regressão da competência moral ao longo da graduação. Justo da competência moral (entendida como a capacidade de resolver conflitos de valores com base nos próprios princípios morais ${ }^{10}$ ), prérequisito, portanto, para uma competência ética ${ }^{11}$ que é, por sua vez, elemento central para a sustentação da democracia e dos direitos humanos. Precisamos então nos perguntar sobre o que acontece com aqueles adolescentes que chegam aos cursos da Área da Saúde cheios de ideais, querendo fazer o bem às pessoas, desejando fazer diferença no mundo em que vivemos, e saem desiludidos e focados na sua inserção no mercado profissional $^{12,13}$ ? 
Adolescentes que vêm animados e cheios de expectativas pela vida universitária, e vão para a vida adulta, cansados como se tivessem terminado uma maratona, uma corrida de obstáculos em busca de um diploma ${ }^{1}$ ? O que acontece nesse período de "formação profissional" que, ao final, mais parece um período de "deformação" ou de "formatação" de mentes, ideais e desejos?

Ocorre que o processo de socialização profissional - aquele no qual aprendemos a cultura e, portanto, os modelos e os valores mais ou menos valorizados pelos pares da profissão escolhida - inclui também os aprendizados do currículo oculto ${ }^{12}$. Ou seja, para além das questões previstas nos projetos pedagógicos de cada curso, todas as vivências acadêmicas (dentro e fora dos muros da universidade), todas as relações das quais participamos (entre colegas, com professores, com pacientes, com instituições), e todos os modelos profissionais com que tomamos contato (as diferentes especialidades e tipos de atuação profissional), desempenham um determinado papel na nossa conformação profissional ${ }^{14}$, nessa nossa nova identidade social que vamos construindo em relação, e que vai nos construindo ao mesmo tempo ${ }^{15}$, dando substância à nossa personalidade moral.

Reconhecer a importância, acolher e, quiçá, compreender os fenômenos psíquicos habituais desse período constitui uma das funções educativas. É, portanto, fundamental entender que o recolhimento da curiosidade e do idealismo não fazem parte do processo de amadurecimento, mas sim de uma dessensibilização ou negação diante do acúmulo de frustrações e conflitos vivenciados e não refletidos, que deixam à margem a esperança de conciliar diferentes valores humanos.

Se a dimensão ética da educação de profissionais de saúde precisa ser valorizada e aprimorada, como por exemplo na Odontologia ${ }^{13,16}$, precisamos analisar mais atentamente o que se passa (e também o que não se passa) em nossos cursos de graduação e na vida universitária. Porque toda competência profissional inclui conhecimentos, habilidades e atitudes. Dito de outra maneira, é o saberconhecer da teoria, o saber-fazer das aulas práticas e o saber-ser da vida cotidiana. Mas, enquanto as habilidades são valorizadas e os conhecimentos técnico-científicos são supervalorizados, as atitudes são relegadas, desprezadas, invisibilizadas. É a "parte subjetiva" da avaliação que atemoriza professores pela pretensa dificuldade de comprovação. É o que se avalia (mal) sob o título de assiduidade e pontualidade, esquecendo-se assim de outros valores e atitudes como o respeito, a empatia, a compreensão, a responsabilidade e a solidariedade, que vemos hoje desbotados em grande parte dos profissionais de saúde.

As competências moral e ética oscilam na dependência das ofertas de oportunidades para o seu desenvolvimento. Os cursos biomédicos costumam ter uma estrutura rígida, hierárquica, autoritária $^{12}$. Reproduzem a sociedade machista e heteronormativa ${ }^{17}$ da qual fazem parte. Não promovem o respeito aos pensamentos divergentes, sejam eles morais ou políticos, e tratam a incerteza como expressão de incompetência $^{18}$. Não incluem uma leitura da sociedade, de suas situações de discriminação, desigualdades e violências, nem mesmo quando estas ocorrem (cotidianamente) no ambiente acadêmico $^{19}$. Não dão suporte à exploração conceitual do mundo dos valores e da moralidade humana. Não priorizam o diálogo e a deliberação ética $^{20}$. Tampouco encorajam a análise de conflitos que mostram potência para o desenvolvimento do raciocínio e do juízo moral. São cursos que consideram cumprir sua missão 
ética ao incluir disciplinas assim nomeadas, mas que não promovem um ethos institucional que prime por seus docentes e discentes, que os priorize, que os reconheça e que deles cuide ${ }^{21}$.

Inviável, portanto, falar em ética nas profissões do cuidado sem analisar o cuidado que se tem com quem ensina e com quem aprende ${ }^{21}$. Exemplo disso é a já constatada escassez de recursos disponíveis para o atendimento às frequentes demandas psíquicas evocadas nesse período $^{22}$. Sofrimento mental, uso de drogas, violência e suicídio ${ }^{22-24}$ são cada vez mais presentes entre os universitários, sem que respostas institucionais sejam implementadas na maior parte das vezes. Assim como os trotes, tais fenômenos são tratados como se fossem exclusivos da vida particular dos estudantes, e não como parte de uma etapa de socialização sobre a qual a universidade detém importante função.

A formação profissional em saúde costuma ocorrer em um ambiente focado no pensamento convergente $^{25}$, que anseia pela resposta correta, pela segurança do conhecido, pela obediência acrítica às regras dos códigos deontológicos, pela manutenção do status quo. Ao não se abordar a dimensão moral, estética e política da vida humana e social na educação do futuro profissional, desperdiçamos uma oportunidade ímpar. Mantemos nossos estudantes no nível convencional da moralidade humana, como diria Lawrence Kohlberg, quem transformou a moralidade em um assunto de pesquisa científica e estabeleceu as bases para a mensuração objetiva da competência moral ${ }^{26}$. Para esse psicólogo norte-americano, eram três os níveis de desenvolvimento e aprendizagem moral: o préconvencional, quando o indivíduo julga moralmente a partir de seu interesse egoísta; o convencional, quando considera justo o que é aceito pelas regras da comunidade; e o pósconvencional, quando distingue princípios universais de normas convencionais, julgando o que é justo, "colocando-se no lugar do outro". A maior parte das pessoas adultas em nossas sociedades contemporâneas não passa do nível convencional como o próprio nome diz, ou seja, não aproveita toda a sua potencialidade ${ }^{5}$. Dito de outra forma, considera que "se está na lei, pode". Pouco importa se nem tudo que é legal, é moral.

A vida universitária deveria ser uma excelente oportunidade para a construção da personalidade moral que constitui a essência da dimensão ética da educação superior. Para tanto, as ações da universidade deveriam estar voltadas para a educação integral dos estudantes - de sua autonomia, humanidade, personalidade e caráter $^{1,4,27}$, ou em outras palavras, para a otimização do ser humano. Isto implicaria um tipo particular de vínculo entre professores e estudantes, e a valorização da influência educativa dos primeiros sobre os segundos. Uma influência que se enraíza no encontro entre eles, porque tem a ver com a humanidade de ambos ${ }^{2}$.

\section{DA HETERONOMIA À AUTONOMIA, DA DEONTOLOGIA À ÉTICA: CONCEPÇÕES E CONFUSÕES}

Posto isso, duas questões centrais à dimensão ética da educação podem ser deduzidas. A primeira diz respeito às nossas concepções de ética. Isto porque o termo "ética" está banalizado. Podemos ouvi-lo e lê-lo nas manchetes da mídia com bastante frequência. $\mathrm{Na}$ linguagem popular também: a ética aparece como sinônimo de moral, como se tratassem, de uma mesma forma, sobre costumes, crenças e caráter, e não como dois distintos níveis lógicos do fenômeno moral, com a ética analisando a moral, tomando-a como objeto ${ }^{27,28}$. As profissões e as instituições também contribuem para a banalização do termo quando reduzem a ética a uma concepção meramente deontológica ${ }^{11-13}$, ou seja, quando a tomam como sinônimo de 
obediência a normas.

Mas ética tem mais a ver com formular perguntas do que com obter respostas. Ética é aquilo que precisamos nas situações de incerteza, justamente quando o bom, o correto, o justo é desconhecido. Quando nos deparamos com um conflito de valores e o melhor que podemos fazer é agir com prudência e responsabilidade. Muito além de buscar em que leis ou em que artigos de um código de ética profissional estaria a solução de um determinado problema, a ética trata de, exaustivamente, compreender os fatos e os valores implicados para então decidir o que devemos fazer ${ }^{20}$, dando margem, inclusive, para a descoberta da insuficiência de determinado código moral no caso em concreto e, portanto, da necessidade de impulsioná-lo adiante.

Nossa crítica não se direciona à deontologia profissional ou aos códigos de ética institucionais ou profissionais. São necessários. Nossa crítica se direciona ao entendimento frequentemente limitado da ética que acabam por fomentar. Ora, se o que se considera "correto" já está normatizado, precisaríamos apenas ser obedientes. Mas, ao analisarmos a obediência enquanto um valor moral nos deparamos com o fato dos valores serem hierarquizáveis, ou seja, em cada tempo e em cada sociedade, estabelecem-se os valores mais e menos valorizados. Também nos deparamos com o fato de que existem diferentes tipos de valores. Existem valores de uso, ou instrumentais, que se sustentam porque promovem valores hierarquicamente superiores: os valores ditos "intrínsecos". São os valores próprios dos seres vivos e das pessoas, como a saúde, a vida, a solidariedade, a justiça, a liberdade, a dignidade e a felicidade, entre tantos outros ${ }^{3,27}$. Assim, considerando que a obediência é um valor instrumental, entendemos que ela pode servir a fins totalmente opostos do ponto de vista moral, na dependência de a quais valores intrínsecos ou desvalores ela está a serviço.

Foi Jeremy Bentham ${ }^{29}$, jurista e filósofo inglês, que no século XVIII tentou unir moral e leis pela primeira vez, fundando o conceito de Deontologia. Desde então, entende-se por Deontologia Aplicada o estudo dos deveres profissionais a partir de um marco ético-jurídico. Fundamental, entretanto, entender que o intento deste filósofo utilitarista em tornar mais prática a ação ética, jamais seria capaz de simplificá-la a tal ponto. Não se pode confundir Deontologia e Ética, nem tampouco Direito e Ética ${ }^{28}$. Tanto o Direito quanto a Deontologia exigem a vivência de mínimos morais, sem os quais a sociedade ou a corporação não "sobreviveriam", e aplicam punições quando são desrespeitados, quando as regras coletivamente pactuadas são descumpridas. É a lógica da chamada "Ética Profissional", que menos confusão provocaria se fosse denominada tão somente de Deontologia Profissional. Já a ética - esta a qual nos referimos - não trata de mínimos, pelo contrário, trata da promoção de máximos. Porque o que ela nos exige não é nada menos que o ótimo. Não por outra razão que o tempo verbal da ética é o modo imperativo: "seja o melhor que você pode ser!" É isto o que nos cobra a ética: a excelência.

Essa ética - reflexão crítica sobre aspectos morais da realidade capaz de nos orientar na vida prática - demanda, no entanto, autonomia moral, não obediência ${ }^{20}$. Uma autonomia só possível quando se leva a cabo a construção da personalidade moral de cada um". "Todos começamos sendo heterônomos, e a conquista da nossa própria humanidade, tanto individual como coletiva, é o logro da autonomia" ${ }^{20}$. Seguir códigos deontológicos não confere nem ao menos estimula autonomia em ninguém.

E daí, decorre a segunda questão central que aqui nos interessa: como ensinar ética então, se o ensino da Ética Profissional tem se mostrado insuficiente para a qualificação de nossos 
profissionais de saúde $?^{30,31}$ Não se trata de uma pergunta simples. São muitos os que buscam respondê-la, alguns deles inclusive coletivamente, como por exemplo, por meio da International Association for Education in Ethics (IAEE) $^{32}$ ou da Red Latinoamericana y del Caribe de Educación en Bioética $(\text { REDLACEB })^{33}$. Mas, um questionamento anterior a esse ainda seria: é possível ensinar ética?

Essa pergunta faz muito sentido dependendo do que entendemos por ensino. Se o compreendemos como a transmissão de determinados conhecimentos, por exemplo, de um determinado conjunto de valores morais como os contidos nos códigos deontológicos, então sim, seria possível. Mas se entendemos que a ética não depende apenas de conhecimentos, mas, sobretudo, de habilidades e de atitudes, então esta concepção tradicional de ensino seria realmente questionável. Haveria de ser mais bem uma vivência - múltiplas vivências - que um ensino. Um aprimoramento no caráter, na personalidade moral ${ }^{5}$, mais que o aprendizado de regras. Haveria que ser oportunidades que permitissem e facilitassem o reconhecimento de valores e contra valores morais: cuidadodescuido, justiça-injustiça, solidariedadeegoísmo, liberdade-autoritarismo, enfim, todos aqueles que se apresentam frente aos profissionais de saúde, sob a forma de conflitos morais, de problemas éticos, demandando de nós um diálogo silencioso, que é a própria atividade do pensamento. Uma análise crítica e, antes de tudo, autocrítica. Um diálogo necessário também com o outro, ampliando nossas perspectivas, fomentando a compreensão de outros pontos de vista que podem relativizar os nossos, aperfeiçoando assim a sensibilidade e a competência moral. E disto trata precisamente a deliberação moral - um método imprescindível para todos os projetos verdadeiramente educativos $^{20}$.

\section{POR UM REPOSICIONAMENTO DOCENTE E INSTITUCIONAL}

Uma pedagogia deliberativa - aquela que busca criar espaços de aprendizagem baseada na argumentação e no diálogo, favorecendo a construção coletiva de atitudes democráticas ${ }^{34}$ requer interlocutores capazes de suportar a angústia que a incerteza costuma suscitar. Professores que exercitem a humildade, a responsabilidade e a dedicação com aqueles em educação. Cientes que, mais do que ensinar, podem promover um ambiente onde o aprendizado significativo ocorra, cresça em complexidade e resulte num verdadeiro ganho de autonomia moral. Por isso, discutir o trote é fundamental, discutir as políticas afirmativas é fundamental, discutir as questões de gênero, as desigualdades sociais, as iniquidades em saúde, o comportamento de pacientes, estudantes, professores e, especialmente, dos próprios profissionais de saúde em suas práticas diárias. Uma disciplina ou um curso de ética isolado em um extenso currículo tende a ser insuficiente diante da força de anos de vida, de escolarização e formação profissional vivenciando situações em que contra valores são banalizados.

Atribui-se a Freud a afirmação de que a psicanálise seria uma "segunda chance" no desenvolvimento psíquico. $\mathrm{Na}$ esteira dessa afirmação, grandes investimentos são feitos e importantes conquistas pessoais são alcançadas em processos analíticos. Mas no caso da construção da personalidade moral, há os que dizem que o caráter vem de casa, que "vem de berço" e que se dali não veio, não há o que nós, professores, possamos fazer. Grande parte dos próprios estudantes também compartilha dessa opinião ao iniciar seu curso universitário ${ }^{22}$. Tal equívoco precisa ser desfeito, pois já restou comprovado que a educação não compete 
somente às famílias, mas também à escola e à universidade ${ }^{1,5,12,29}$, porque a construção da personalidade moral não tem idade para acabar. Ela não se completa com a maioridade, é processo permanente que acompanha nossa vida biográfica $^{5}$, assim como nossas construções de identidade, especialmente as que se dão a partir do trabalho. ${ }^{15}$ Agora bem, nosso desenvolvimento moral pode estagnar, regredir ou evoluir, na dependência do contexto em que estamos inseridos, seja ele familiar, escolar, laboral, social.

Para finalizar, cabe lembrar que ética implica em reciprocidade, em correspondência mútua. Assim, se queremos que nossos alunos se dediquem, devemos nos dedicar. E se queremos que os docentes da instituição da qual fazemos parte se comprometam, devemos nos esforçar para que a instituição com todos se comprometa. Porque como dizia Ghandi, "precisamos ser a transformação que queremos ver no mundo".

\section{ABSTRACT \\ Training $x$ education, Deontology $x$ ethics: rethinking concepts and repositioning professors}

Starting from teachers' concerns and reflections, we seek to problematize some concepts often taken as synonyms in the context of professionals' health education, revealing alternative conceptions of ethical and pedagogical doing. The analysis focuses on ethics hegemonic idea that forms a particular meaning for the expression "ethics in training," in opposition to what could be called an "ethical dimension of education." Through a dialogical writing about common topics to every professor, the rationale is to provoke the reader to his/her academic praxis examination and to question what are we doing in universities: developing vocational training or higher education? The arguments expressed in this essay seek to encourage the (self) questioning so that each one responds, in his or her way, and then collectively, to the essential question regarding ethics: "What should we do"?

Descriptors: Ethics. Moral Development. Education, Higher. Professional Training. Universities.

\section{REFERÊNCIAS}

1. Esteban F, Román B. ¿Quo Vadis, Universidad? Barcelona: UOC; 2016.

2. Esteban, F. El profesor universitario y su quehacer docente: la perspectiva comunitarista. Rev Ped Esp. 2013; 71(255):227-42.

3. Gracia D. Misión de la Universidad. In: Construyendo valores. Madrid: Tricastela, 2013. p. 237-65.

4. Finkler M. Formação profissional e/ou educação universitária: de onde viemos, para onde vamos? Interface Comun Saúde Educ. 2017; 21(61):465-8

5. Puig JM. A construção da personalidade moral. São Paulo: Ática, 1998.

6. Lind G. Moral regression in medical students and their learning environment. Rev Bras Educ Med. 2000; 24(3):24-33.

7. Feitosa HN, Rego S, Bataglia P, Rego G, Nunes R. competência de juízo moral dos estudantes de Medicina. Rev Bras Educ Med. 2013; 37(1):5- 14.

8. Freitas SFT, Kowaleski DF, Boing AF, Oliveira WF. stages of moral development among Brazilian dental students. J Dent Educ. 2006; 70(3):296-306.

9. Oliveira MS. Desenvolvimento da competência de juízo moral e ambiente de ensino-aprendizagem: uma investigação com estudantes de graduação em enfermagem [Dissertação]. Rio de Janeiro: Fiocruz; 2008 146p.

10. Lind G. O significado e medida da competência moral revisitada: um modelo do duplo aspecto da competência moral. Psicol Reflex Crít. 2000; 13(3):399-416.

11. Arouca R, Rego S, Machado MH. O papel da escola na educação moral de estudantes de Odontologia. Rev Bras Odontol. 2008; 65(2):211-15.

12. Rego S. Formação ética dos médicos: saindo 
da adolescência com a vida (dos outros) nas mãos. Rio de Janeiro: Fiocruz, 2003. 184p.

13. Finkler M, Ramos FRS. La dimensión ética de la educación superior en Odontología: un estudio en Brasil. Bordón. 2017;69(4):3549.

14. Finkler M, Caetano JC, Ramos FRS. Um marco conceitual para o estudo da dimensão ética da formação profissional em saúde. In: Verdi MI, Caponi S, Gabrielli R, Hellmann F. Florianópolis: DIOESC, 2012. p.171-89.

15. Dubar C. A socialização: construção das identidades sociais e profissionais. São Paulo: Martins Fontes. 2005.

16. Patrick AC. A review of teaching ethics in the dental curriculum: challenges and future developments. Eur J Dent Educ. 2017;21(4):e114-8.

17. Moscheta MS, Moretti-Pires RO. Gênero, sociedade e transformações. Saúde Transform Soc. 2016;7(3):i-ii.

18. Simpkin AL, Schwartztein TM. Tolerating uncertainty - the next medical revolution? $\mathrm{N}$ Engl J Med. 2016; 375(18)1713-5.

19. Rego S, Palácios M. Abusos na escola médica - editorial. Rev Bras Educ Med. 2014; 38(4):417-8.

20. Gracia D. Teoria y práctica de la deliberación moral. In: Feito L; Gracia D, Sanchez M. Bioética: el estado de la cuestión. Madrid: Tricastela, 2011. p.10152.

21. Finkler M, Caetano JC, Ramos FRS. O cuidado ético-pedagógico no processo de socialização profissional: por uma formação ética. Interface Comun Saúde Educ. 2012; 16(43):981-93.

22. Millan LR, Arruda PCV. Assistência psicológica ao estudante de Medicina: 21 anos de experiência. Rev Assoc Med Bras. 2008; 54(1):90-4.

23. Lageborn CT, Liung R, Vaez M, Dahlin M. Ongoing university studies and the risk of suicide: a register-based nationwide cohort study of 5 million young and middle-aged individuals in Sweden, 1993-2011. BMJ Open. 2017;7(3):1-8.

24. Vasconcelos TC, Dias BRT, Andrade LR,
Melo GF, Barbosa L, Souza E. Prevalência de sintomas de ansiedade e depressão em estudantes de Medicina. Rev Bras Educ Med. 2015; 29(1):135-42.

25. Self DJ, Scrader DE, Baldwin DCJr, Wolinsky FD. The moral development of medical studants: a pilot study of the possible influence of medical education. Med Educ. 1993; 27(1):26-34.

26. Lind G. Moral competence test. Definitions; 2017. [Acesso em: 11 nov. 2017]. Disponível em: https://www.unikonstanz.de/ag-moral/mut/mjt-engl.htm.

27. Cortina A. El mundo de los valores: ética y educación. Santafé de Bogotá: El Buho, 1997.

28. Cortina A. O fazer ético: guia para educação moral. São Paulo: Moderna, 2003.

29. Bentham J. Deontologia o ciência de la moral. Valencia: Mallen y Sobrinos, 1836.

30. Crutchfield P, Johnson JC, Brandt L, Fleming D. The limits of deontology in dental ethics education. Int J Ethics Educ. 2016; 1:183-200.

31. Pyrrho M, Prado MM, Cordon J, Garrafa V. Análise bioética do Código de Ética Odontológica brasileiro. Ciênc Saúde Coletiva 2009; 14(5):1911-8.

32. International Association for Etichs Education. [Acesso em: 11 nov. 2017]. Disponível em: https://www.ethicsassociation.org/

33. Red Latinoamericana y del Caribe de Educación en Bioética. [Acesso em: 11 nov. 2017]. Disponível em: http://redlaceb.com/ 34. Cole HJ. Teaching, Practicing, and Performing Deliberative Democracy in the Classroom. J Public Delib. 2013;(2):1-36.

\section{Correspondência para:}

Mirelle Finkler

e-mail: mirelle.finkler@ufsc.br

Disciplinas de Interação Comunitária - Sala

147/CCS/UFSC

Campus Reitor João David Ferreira Lima, s/n Trindade

88040-900 Florianópolis - SC 